\title{
Neighbourhoods and dementia: An updated realist review of the qualitative literature to inform contemporary practice and policy understanding
}

\begin{abstract}
This realist review of the literature provided a contemporary understanding of neighbourhoods and dementia and described how people living with dementia and their neighbourhood interacted via ongoing place-making and remaking processes. Drawing on 44 articles, neighbourhoods were revealed to have fluid and dynamic qualities where people with dementia used their strength and resources to connect to significant people and places. The review also indicated that the person with dementia-neighbourhood relationship was underpinned by four themes: 'home', 'social interactions', 'activities' and 'transportation'. Further research is encouraged to use innovative, participatory methods to explore the neighbourhood-dementia nexus in depth whilst paying close attention to social inclusion and diversity.
\end{abstract}

Key words: dementia; neighbourhood; review; home; social interactions; relationship. 


\section{Introduction}

The growing ageing population leads to an increasing number of people living with dementia (Alzheimer's Disease International, 2015; Department of Health, 2015). To support this population, the World Health Organisation and Alzheimer's Disease International (2012) have highlighted the importance of 'promoting a dementia-friendly society globally' to enable those living with the condition to age in place and to remain connected to the community. This initiative has been well established in Australia, Belgium, Canada, Germany and the UK (Turner \& Moken, 2016). By living in dementia-friendly communities, the aspiration is that the specific needs of people living with dementia will be met and they enabled to participate in and contribute to society (Alzheimer's Society, 2013; Turner \& Morken, 2016) and gain a sense of belonging (Milton, 2012). The dementia-friendly initiative has paved the way to:

Remind society that people with dementia have the same rights as everyone else to be treated with dignity and respect, to lead independent, autonomous lives and to continue to be active citizens in society whose opinions are heard and acted upon. (Mitchell 2012, p.1)

Supporting people living with dementia to have equal rights as others in society has been further championed by the Mental Health Foundation (2015), claiming that people who have impairment(s) caused by a condition are disabled or restricted by society rather than by their condition. This suggests that society needs to enable people with impairments to ensure equal rights with other citizens (Oliver, Sapey, \& Thomas, 2012). As such, the discourse around dementia has inevitably shifted towards a rights-based agenda, promoting both the social model of disability and the meaningful connections of people living with dementia to their everyday experience in their neighbourhood (Bartlett \& O’Connor, 2007, 2010; Keady et al., 2012).

To provide clarity on the concept of 'neighbourhood', it is essential to understand how 'community' is perceived over time. Historically, 'community' focused upon the geographical aspect (a substitute term for locality) and/or social relationships (well beyond a geographical location) (Douglas, 2010; Gusfield, 1975). Community has emotional overtones, implies a degree of attachment and belonging, and offers beneficial contributions 
to establish a strong and vibrant society. On the contrary, it has negative anti-social goals, aiming to exclude those who do not conform to an expected behaviour or condition; this can be associated with class, race, gender, sexuality, or disability and are classed as 'dark communities' (Douglas, 2010). In modern society, the development of technologies has formed a new dimension where people interact with that community via the internet; this leads to people living with their 'own worlds' (Brock, 2008) and weakens traditional placebased aspect (Douglas, 2010).

However, 'neighbourhood' is more localised, with a perceived geographical boundary. Neighbourhood as a complex system derived from individual interactions with geographical and social variations, becomes a complex causal combination that can influence local population health. This is illustrated through Blackman's book 'Placing Health' (2006) where he examines complex interrelationships within a neighbourhood. He states that the 'neighbourhood' is 'a walkable zone of experience' at the 'smallest significant socio-spatial scale of the societies of which they are part' (p.2) and that the 'neighbourhood' is a geographical space that holds physical and social attributes. Therefore, the experience of neighbourhood living closely links to the health status of people living with dementia (Satariano, 2006) and especially resonates with the concept of social health (Huber et al., 2011), which relates to balancing opportunities and limitations, affected by external factors such as social and environmental elements (Vernooij-Dassen \& Jeon, 2016). Social health acknowledges that in the environmental context, the state of well-being can be achieved by making adaptations to minimise constraints and by grasping opportunities to reclaim certain levels of abilities affected by the condition(s) (Huber et al., 2011). Here, 'being in place' plays an important role in the experience of neighbourhood living and is about the accumulation and assimilation of multi-layered meanings of place via the continual processes of place-making and remaking (Rowles \& Bernard, 2013). 'Place' emerges through people's interactions with other people, biological entities (such as animals and plants) and/or objects (such as cars) (Conradson, 2005). Being in place helps to maintain a personal sense of attachment and secure identity and it facilitates an assumption of stability in an individual's geography of social relations (Massey, 1994). However, maintaining a sense of being in place for people living with dementia can be challenging when, over time, the familiarity of local 
landmarks can start to become unfamiliar, a process a person living with dementia recently described as place-attachment disruption (Calvert et al., 2020).

To further understand this complex situation, close attention should be paid to the lived experience of dementia in an everyday context and how people living with dementia connect to their localities and neighbourhood. As such, interest in 'neighbourhood' where the everyday life of people living with dementia plays out has been growing (Ward et al., 2018). For instance, in a realist review conducted nearly a decade ago, Keady et al. (2012) explored neighbourhoods and dementia in the context of health and social care, and highlighted how outdoor spaces, the built environment and everyday technologies influenced the daily living of people with dementia. However, the article identified various knowledge gaps and was based upon 18 published articles. In the years since this 2012 review, there has been considerable attention paid to neighbourhoods, dementia and outdoor spaces. Therefore, this article aims to update the 2012 review and to address the identified gaps by understanding the relationship and interaction between the neighbourhood as both physical and social environments, and people living with dementia as active 'place-makers', and to more fully understand their definition of a neighbourhood.

\section{Methodology}

This article adapted a realist review method (Pawson et al., 2005; O'Campo et al., 2009) and adhered to the subsequent steps: i) clarifying the scope of the review, ii) identifying and collecting evidence, iii) appraising the evidence, iv) analysing and synthesising the evidence with theory, and v) formulating themes as detailed in the previous review (Keady et al., 2012). The rationale behind the chosen method was that the realist review method was used in the 2012 review and that the method helped to indicate "what works for whom, in what circumstances, in what respects, and how' (Pawson et al., 2005, p.21), thereby providing context-specific evidence to guide practice in dementia care.

Each review finding was then assessed using GRADE-CERQual (2018) to understand the extent to which an individual finding reasonably represented the phenomenon of interest. There were two reasons for applying GRADE-CERQual to the findings from this qualitative 
evidence synthesis. First, it offered a systematic and transparent method for assessing how much confidence to place in each individual review finding across studies (Lewin et al., 2018). Second, it provided a structured process for developing and presenting evidence in a succinct and transparent summary of qualitative findings, aiming to illustrate the review findings, the CERQual assessment of confidence in each finding and an explanation of the assessment (Guyatt et al. 2011; Lewin et al., 2018). Therefore, the use of GRADE-CERQual in this review would assist decision makers in applying the findings to dementia care and policy.

In line with the realist review method, a systematic approach was applied during the literature collation and reporting stage.

\section{Search strategy and inclusion criteria}

Computerised searches, using the search string/key terms (figure 1), were conducted across the following databases: AMED, BNI, CINAHL, Cochrane Database of systematic reviews, EMBASE, HEB, HMIC, MEDLINE, PsycINFO, and Social care online.

Figure 1. Search string/terms

$$
\begin{aligned}
& \text { (Alzheimer[s] OR “dementia”) AND (“older people” OR "ageing” OR "mental health" } \\
& \text { OR “disadvantage" OR “inequalities” OR “carer[s]”) AND ("neighbourhood[s]” OR } \\
& \text { “environment” OR “community” OR “space” OR "place” OR “outdoor” OR "housing” } \\
& \text { OR "home") OR ("neighbour[s]" OR "social tie[s]" OR "network[s]") OR ("policy” OR } \\
& \text { “social model of disability" OR “citizen[ship]” OR "empowerment” OR "promotion” OR } \\
& \text { "quality of life” OR "well-being” OR “identity” OR "autonomy” OR “independence” OR } \\
& \text { “personhood” OR "belonging” OR “attachment” OR "loneliness" OR “exclusion” OR } \\
& \text { “social health”) OR (“transport” OR “technology” OR “walkability” OR "physical } \\
& \text { activity” OR “education” OR “design”) }
\end{aligned}
$$

This review included the studies indicating: i) people living with dementia's understanding of neighbourhood; ii) their experiences of living in their neighbourhood; or iii) how people living with dementia and neighbourhood might influence one another. In line with the 2012 review, the included studies had a potential shift towards a social model of disability, 
emphasising how people living with dementia were disabled and/or enabled by society, beyond the explicit wording of 'social model of disability'. Therefore, we chose only studies that were published from January 2012 to May 2018 as any papers published before 2012 were included in the previous review (Keady et al., 2012) and considered out of date, with little or no attention paid to the social model of disability. We also selected studies that were qualitative in design, including mixed-methods and reviews of qualitative studies, to seek a clearer understanding of people living with dementia's everyday experiences. Furthermore, we conducted focused searches in the areas of people with young-onset dementia, transport and driving cessation, neighbourhood design and leisure activity. We excluded the studies that focused upon the following aspects:

- Medical, genetic or neurological reasons and treatments for dementia.

- Clinical trials of medications for dementia.

- Mixed populations (such as stroke and dementia) without differentiations between groups in the results.

- End-of-life care.

- Treatments, clinical therapies, or the views of professional caregivers.

- Studies drawing upon a biomedical model with a focus upon symptoms and behaviour.

Where a single author wrote one or more journal articles presenting an account of their experience, only the most recent article was included in the analysis to avoid that individual's account being over-represented in the final analysis.

\section{Quality assessment and data synthesis}

The first author independently extracted data from studies that met the inclusion criteria and then critically appraised these papers using methodological assessment tools from the Critical Appraisal Skills Programme (2018). Data extraction and quality assessment were conducted using a standardised evidence table. The overall assessment of the methodological quality for each study was described as 'high', 'medium', 'low', or 'very low'. No studies were excluded as a result of the quality assessment; rather, the methodological rigor of each study 
contributed to the confidence assessments of relevant review findings, which derived from evidence synthesis and triangulation.

In accordance with the revised realist review method, data synthesis aimed to identify people living with dementia's definition of a neighbourhood and to explore how they, as active 'place-makers', interact with their own neighbourhood. Included papers were systematically reviewed, coded and analysed. The analysis involved several stages: i) repeatedly reading each study; ii) identifying and coding the data; iii) extracting the coded information for synthesis; iv) identifying patterns and themes with theory, while attending to the weight of evidence and to evidence supporting and questioning hypothesized theories; and v) formulating themes and underpinning theory in relation to the purpose of the review. This was then followed by Patton's (1999) triangulation to analyse the data in relation to the context in which they were produced, thereby enhancing the quality and credibility of data analysis and synthesis.

The work then moved on to assess the confidence of each review finding (theme) that emerged from the included studies using GRADE-CERQual (2018) which includes four components: methodological limitations, relevance, coherence and adequacy. The methodological limitations of the individual studies contributing to each review finding were assessed based upon the outcomes of using CASP checklists as described previously. According to GRADE-CERQual (2018), the relevance to the review question of the individual studies, contributing to a review finding, was assessed based on the extent to which the review finding would be applicable to the context (population, phenomenon of interest, setting and outcomes) specified in the review question. The coherence was assessed by exploring how clear and cogent the fit would be between the data from the included studies and the review finding. The adequacy of the data was assessed depending upon the degree of richness and quantity of data supporting a review finding. Based on an overall assessment of these components, the confidence level was described as 'high', 'moderate', 'low' or 'very low'; a summary table was then created to present a list of key qualitative findings and associated assessment results. All the activities were independently carried out by the first author and were reviewed by the other authors for quality assurance; any differences were discussed and resolved. 


\section{Results}

Of the 22,310 results identified through the searches, 44 studies were selected and analysed as the core literature, including 34 primary studies and 10 reviews (figure 2). Qualitative assessment of the 44 included articles revealed that seven studies presented serious concerns ([partially] unclear research design, recruitment, data collection and data analysis methods), four with moderate concerns (partially unclear research design, recruitment and data analysis methods), 20 with minor concerns (partially unclear recruitment or data analysis methods) and 13 with no or very minor concerns.

Figure 2. Selected studies flowchart

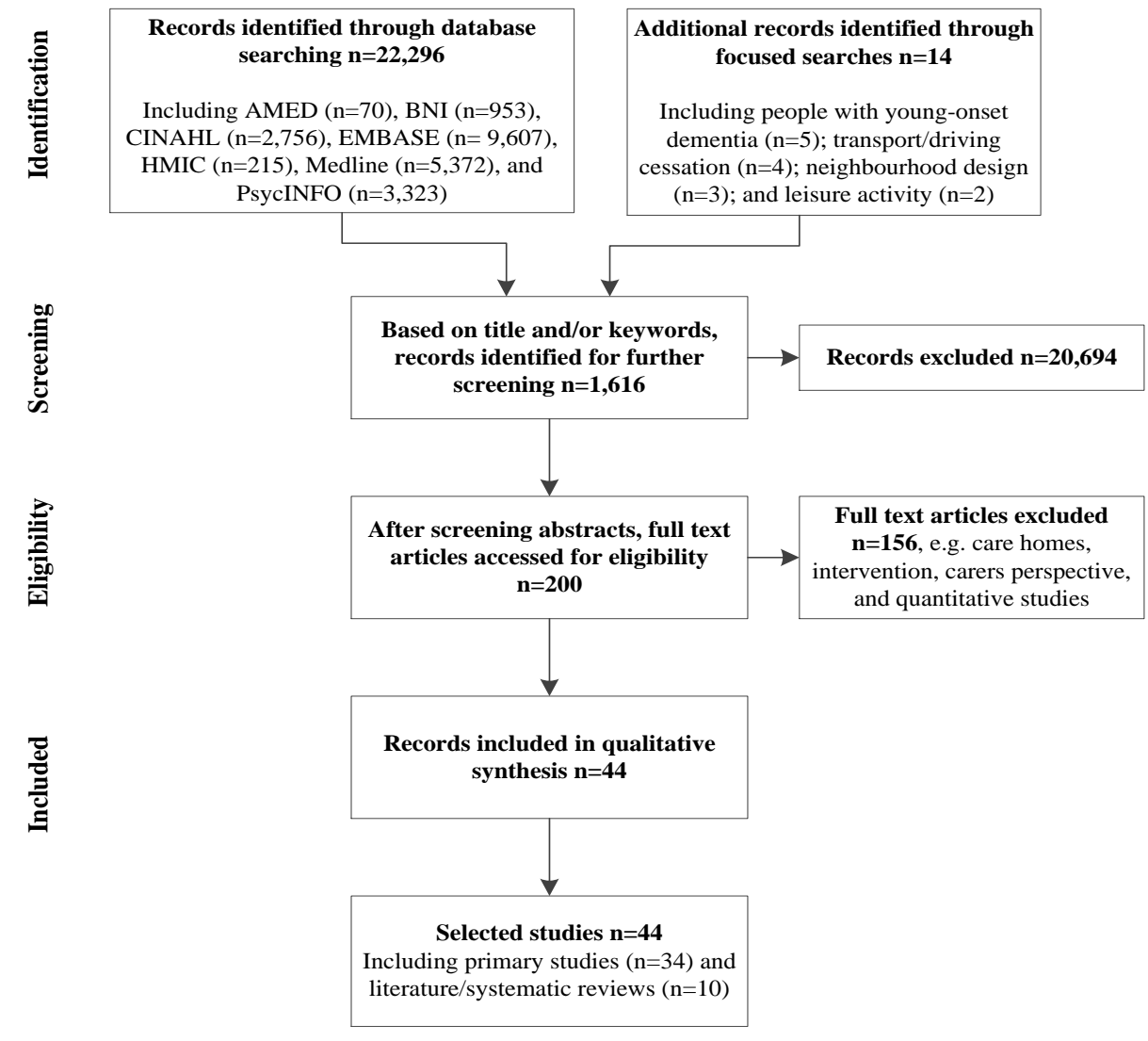

Whilst all the included studies focused upon people living with dementia, the total number of this population was unclear as eight studies failed to specify the sample size. In terms of the 
stages of dementia, seven studies stressed all stages, 13 studies emphasised mild and/or moderate dementia, and 24 studies did not provide clear information. Of the 44 studies, 23 were conducted in the UK, two were international studies, and the remainder carried out in various countries, such as Australia, USA, France, Norway, and so forth. Nevertheless, the settings for all the selected studies were based in local communities, even though the geographical definitions and terms used varied, such as neighbourhood, community and city. According to the purpose of the review, all the included studies have been grouped into two meta-themes, namely 'perspectives on neighbourhood' and 'person-neighbourhood relationships', with the latter meta-theme being supported by four themes (table 1). Within each meta-theme or theme, the confidence of each key finding has been assessed (table 2). 
Table 1. All included studies and associated meta-themes or themes

\begin{tabular}{|c|c|c|c|}
\hline \multicolumn{4}{|c|}{ Perspectives on neighbourhood } \\
\hline \multicolumn{4}{|c|}{$\begin{array}{l}\text { • Crampton, Dean, \& Eley, 2012; Górska, Forsyth, \& Maciver, 2017; Li et al., 2019; Odzakovic, Hellström, Ward, \& Kullberg, 2018; Ward et al., } 2018 \\
\text { Person-neighbourhood relationships }\end{array}$} \\
\hline Theme 1: Home & Theme 2: Social interactions & Theme 3: Activities & Theme 4: Transportation \\
\hline $\begin{array}{l}\text { 1. Li et al., } 2019 \\
\text { 2. Lloyd \& Stirling, } 2015 \\
\text { 3. Górska, Forsyth, \& } \\
\text { Maciver, 2018 } \\
\text { 4. Soilemezi, Drahota, } \\
\text { Crossland, \& Stores, } \\
2017 \\
\text { 5. Ward et al., } 2018\end{array}$ & $\begin{array}{ll}\text { 1. } & \text { Górska et al., } 2018 \\
\text { 2. } & \text { Johnston \& Terp, } 2015 \\
\text { 3. Li et al., 2019 } \\
\text { 4. } \text { Ruthirakuhan et al., 2012 } \\
\text { 5. Samsi \& Manthorpe, 2013 } \\
\text { 6. Smebye \& Kirkewold, } 2013 \\
\text { 7. } \text { Tranvåg, Petersen, \& Nåden, } \\
\text { 2014 } \\
\text { 8. Ward et al., } 2018 \\
\text { 9. Wiersma \& Denton, } 2016 \\
\text { 10. Wiersma et al., 2016 } \\
\text { 11. Wolverson, Clarke, \& Moniz- } \\
\text { Cook, 2016 }\end{array}$ & $\begin{array}{l}\text { 1. Bowes, Dawson, Jepson, \& McCabe, } 2013 \\
\text { 2. Camic, Williams, \& Meeten, } 2013 \\
\text { 3. Carone, Tischler, \& Dening, } 2014 \\
\text { 4. Chaplin \& Davidson, } 2016 \\
\text { 5. Clark, Murphy, Jameson-Allen, \& Wilkins, } 2015 \\
\text { 6. Fortune \& McKeown, 2016 } \\
\text { 7. Hewitt, Watts, Hussey, Thrive, \& Williams, } 2013 \\
\text { 8. Jaaniste, Linnell, Ollerton, \& Slewa-Younan, } 2015 \\
\text { 9. Johnston \& Terp, } 2015 \\
\text { 10. Mapes, } 2018 \\
\text { 11. Malthouse \& Fox, } 2014 \\
\text { 12. Mayrhofer, Mathie, McKeown, Bunn, \& Goodman, } 2017 \\
\text { 13. McCulloch, Robertson, \& Kirkpatrick, } 2016 \\
\text { 14. Osman, Tischler, \& Schneider, 2016 } \\
\text { 15. Phinney, Kelson, Baumbusch, O'Connor, \& Purves, } 2016 \\
\text { 16. Richardson et al., 2016 } \\
\text { 17. Roach \& Drummond, 2014 } \\
\text { 18. Rabanal, Chatwin, Walker, O'Sullivan, \& Williamson } 2018 \\
\text { 19. Roach, Drummond, \& Keady, } 2016 \\
\text { 20. Tuppen, 2012 } \\
\text { 21. van Alphen, Hortobágyi, \& van Heuvelen, } 2016 \\
\text { 22. Wright. } 2016\end{array}$ & $\begin{array}{ll}\text { 1. Andrew, Traynor, \& Iverson, } \\
2015 \\
\text { 2. Carmody, Traynor, \& } \\
\text { Iverson, 2012 } \\
\text { 3. Innes, Page, \& Cutler, } 2016 \\
\text { 4. Lddle, Allen, Bennett, \& Lie, } \\
2013 \\
\text { 5. Risser et al., } 2015\end{array}$ \\
\hline
\end{tabular}


Table 2. CERQual summary of key qualitative findings

\begin{tabular}{|c|c|c|c|}
\hline \multicolumn{4}{|c|}{$\begin{array}{l}\text { Objective: to synthesise qualitative evidence on people living with dementia's perspectives of, and their relationships with, their neighbourhood as both } \\
\text { physical and social environments. }\end{array}$} \\
\hline $\begin{array}{l}\text { Home was a central hub and starting point to } \\
\text { neighbourhood connection and was an important } \\
\text { place with profound significance and emotional } \\
\text { attachment, being the centre of people living with } \\
\text { dementia's lives. }\end{array}$ & $\begin{array}{l}\text { Li et al., 2019; } \\
\text { Soilemezi et al., 2017; } \\
\text { Ward et al., } 2018\end{array}$ & $\begin{array}{l}\text { High } \\
\text { confidence }\end{array}$ & $\begin{array}{l}3 \text { studies with very minor concerns about methodological } \\
\text { limitations, coherence and adequacy. } 1 \text { study (Soilemezi et al.) } \\
\text { with moderate concerns about relevance. } 3 \text { studies from the } \\
\text { UK. }\end{array}$ \\
\hline
\end{tabular}




\begin{tabular}{|c|c|c|c|}
\hline $\begin{array}{l}\text { Social interactions of people living with dementia } \\
\text { ranged across spousal carers, family, friends, } \\
\text { neighbours and care professionals. Experiences of } \\
\text { such interactions influenced personhood and } \\
\text { relational citizenship, particularly through everyday } \\
\text { communication and processes of engagement. }\end{array}$ & $\begin{array}{l}\text { Górska et al., 2017; Li } \\
\text { et al., 2019; } \\
\text { Ruthirakuhan et al., } \\
\text { 2012; Samsi \& } \\
\text { Manthorpe, 2013; } \\
\text { Smebye \& Kirkewold, } \\
\text { 2013; Tranvåg et al., } \\
\text { 2014; Ward et al., } \\
\text { 2018; Wiersma \& } \\
\text { Denton, 2016; } \\
\text { Wolverson et al., } 2016\end{array}$ & $\begin{array}{l}\text { High } \\
\text { confidence }\end{array}$ & $\begin{array}{l}1 \text { study (Ruthirakuhan et al.) with serious methodological } \\
\text { limitations and } 3 \text { studies (Górska et al.; Ward et al.; Smebye \& } \\
\text { Kirkewold) with minor concerns. } 1 \text { study (Ruthirakuhan et al.) } \\
\text { with moderate concerns about coherence. } 1 \text { study (Wiersma \& } \\
\text { Denton) with serious concerns about adequacy and } 1 \text { study } \\
\text { (Ruthirakuhan et al.) with moderate concerns, and } 3 \text { studies } \\
\text { (Samsi \& Manthorpe; Smebye \& Kirkewold; Tranvåg et al.) } \\
\text { with minor concerns. } 3 \text { studies (Górska et al.; Samsi \& } \\
\text { Manthorpe; Smebye \& Kirkewold) with serious concerns about } \\
\text { relevance and } 4 \text { studies (Ruthirakuhan et al.; Tranvåg et al; } \\
\text { Wiersma \& Denton; Wolverson et al.) with moderate concerns. } \\
4 \text { studies from the UK, } 1 \text { from Norway, } 2 \text { from Canada and } 1 \\
\text { international study. }\end{array}$ \\
\hline $\begin{array}{l}\text { Couple's relationships affected their bonds and } \\
\text { abilities to face, and live with, dementia, but } \\
\text { importantly impacts upon independence, dignity, } \\
\text { self-esteem, social connections and physical health. }\end{array}$ & $\begin{array}{l}\text { Johnston \& Terp, } \\
\text { 2015; Li et al., 2019; } \\
\text { Ruthirakuhan et al., } \\
\text { 2012; Tranvåg et al., } \\
\text { 2014; Wiersma et al., } \\
\text { 2016 }\end{array}$ & $\begin{array}{l}\text { Moderate } \\
\text { confidence }\end{array}$ & $\begin{array}{l}1 \text { study (Wiersma et al.) with minor concerns methodological } \\
\text { limitations, } 1 \text { (Johnston \& Terp) with moderate concerns, and } 1 \\
\text { (Ruthirakuhan) with serious concerns. } 2 \text { studies (Johnston \& } \\
\text { Terp; Ruthirakuhan et al.) with moderate concerns about } \\
\text { coherence and adequacy. } 4 \text { studies (Johnston \& Terp; } \\
\text { Ruthirakuhan et al.; Tranvåg et al.; Wiersma et al.) with } \\
\text { moderate concerns about relevance. } 2 \text { studies from Canada, } 1 \\
\text { from the US, } 1 \text { from Norway and } 1 \text { from the UK. }\end{array}$ \\
\hline $\begin{array}{l}\text { For people with young-onset dementia, due to the } \\
\text { (potential) traumatic cessation of work, the desire } \\
\text { for meaningful activities was crucial and beneficial, } \\
\text { including a preserved sense of purpose, dignity and } \\
\text { personhood, supported social inclusion and } \\
\text { belonging, maintained continuity in their } \\
\text { biographies, enhanced self-esteem, and increased } \\
\text { the ability to positively cope with transitions, } \\
\text { ultimately improved well-being and cognitive } \\
\text { functioning. }\end{array}$ & $\begin{array}{l}\text { Carone et al., 2014; } \\
\text { Chaplin \& Davidson, } \\
\text { 2016; Hewitt et al., } \\
\text { 2013; Mayrhofer et al., } \\
\text { 2017; McCulloch et } \\
\text { al., 2016; Phinney et } \\
\text { al., 2016; Rabanal et } \\
\text { al., 2018; Roach \& } \\
\text { Drummond, 2014; } \\
\text { Roach et al., 2016 }\end{array}$ & $\begin{array}{l}\text { Moderate } \\
\text { confidence }\end{array}$ & $\begin{array}{l}2 \text { studies (Chaplin \& Davidson; Hewitt et al.) with moderate } \\
\text { concerns about methodology and } 6 \text { studies (Carone et al.; } \\
\text { Mayrhofer et al.; Phinney et al.; Roach \& Drummond; Rabanal } \\
\text { et al.; Roach et al.) with minor concerns. } 4 \text { studies (Phinney et } \\
\text { al; Roach \& Drummond; Roach et al.; Hewitt et al.) with } \\
\text { moderate concerns about coherence. } 1 \text { study (Roach \& } \\
\text { Drummond) with serious concerns about data adequacy, } 3 \\
\text { studies (Carone et al.; Hewitt et al.; Roach et al.) with moderate } \\
\text { concerns. All } 9 \text { studies with moderate concerns about } \\
\text { relevance. } 6 \text { studies from the UK and } 3 \text { from Canada. }\end{array}$ \\
\hline
\end{tabular}


Driving cessation increased road safety, yet it was associated with the loss of identity, self-worth, and community engagement, ultimately leading to a 'shrinking world'. Following driving cessation, providing better alternative transportation and community support were crucial.
Andrew et al., 2015;

Carmody et al., 2012;

Liddle et al., 2013;

Risser et al., 2015
Moderate

confidence

1 study (Carmody et al.) with serious methodological

limitations and 2 studies (Andrew et al.; Risser et al.) with minor concerns. 2 studies (Carmody et al.; Risser et al.) with moderate concerns about coherence. 1 study (Andrew et al.) with serious concerns about adequacy and 3 studies with moderate concerns. 4 studies with moderate concerns about relevance. 3 studies from Australia and 1 from Sweden. 


\section{Perspectives on neighbourhood}

According to this review, neighbourhoods were revealed to have fluid and dynamic qualities where people living with dementia used their strength and available resources to connect to significant people and important places and so gained a sense of belonging and attachment (Li et al., 2019; Odzakovic et al., 2018; Ward et al., 2018). Ward et al. (2018), using a longitudinal, comparative design framed by a participatory approach, studied how neighbourhood could support people living with dementia and their carers to remain active socially and physically. Based on the first 10 to 11 individuals or dyads living with dementia from the North of England and the Central Belt of Scotland, the findings revealed the concept of the 'lived neighbourhood' where the participants used their potential and capabilities to offset the limitations they encountered. This concept is enriched by the Swedish cohort from the same study where walking interviews were applied with 14 community-dwelling people living with dementia (11 men and three women). This strand of the study demonstrated that the 'essence' of a neighbourhood was "a walkable area of subjective significance and social opportunity in which to move freely and feel rejuvenated", highlighting a sense of attachment (Odzakovic et al., 2018).

The understanding of the 'lived neighbourhood' is supplemented by Li et al. (2019) who explored the meaning, construction and places of a neighbourhood with five people with mild dementia (four women and one man; two persons living with dementia used wheelchairs when going out and about) and their care partners through a longitudinal narrative, participatory approach. The findings highlighted the 'connected neighbourhood' concept and illustrated that a 'neighbourhood' was a place where the person living with dementia lived and was a product of their connections with 'people' and 'places' and access to 'resources', coupled with their interpretations of being in place within a fluid geographical boundary. It is this important sense of connection that enabled people living with dementia to construct their neighbourhood with significant people with whom they had close bonds (Li et al., 2019), and through important places, where their life stories were often embedded (Li et al., 2019; Odzakovic et al., 2018; Ward et al., 2018).

In summary, the principal findings revealed that a neighbourhood was constituted through people living with dementia's interaction with 'places', 'people' and 'resources' and such a 
neighbourhood enabled people living with dementia to feel connected to, and to strive for continuity in, the world around them (Crampton, Dean, \& Eley 2012; Górska, Forsyth, \& Maciver, 2017; Li et al., 2019; Odzakovic et al., 2018). Continuing interaction with social and physical environments demonstrated people living with dementia as active 'placemakers' to constantly construct their own neighbourhood in a meaningful way.

\section{Person-neighbourhood relationships}

The dynamic, multi-layered, person-neighbourhood relationships are organised through four themes, namely 'home', 'social interactions', 'activities' and 'transportation'. These themes illustrated people living with dementia's experiences of interacting with their neighbourhood, that held both physical and social attributes; presented how they overcame challenges and used opportunities in their everyday living to maintain a sense of neighbourhood connection; and highlighted the important role that society played in the lived experience of dementia.

\section{Theme 1: Home}

The theme of 'home' was derived from five studies and was supported by three sub-themes, namely 'meaning of home', 'home modification and adaptation' and 'home-neighbourhood connection'. This theme illustrated how the geographical experience affected the meaning of home and how people living with dementia balanced challenges and opportunities in their daily lives, with the purpose of maintaining or regaining a sense of continuity and stability in their lives.

\section{Meaning of home}

Home was a central hub and starting point to neighbourhood connection and was an important place with profound significance and emotional attachment, often being the centre of people living with dementia's lives (Li et al., 2019; Soilemezi, Drahota, Crossland, \& Stores, 2017; Ward et al., 2018). The significance of the home was theorised by Soilemezi et al. (2017) who reviewed 40 qualitative studies and found that home was i) a centre of socialisation, ii) a locus of autonomy and control, iii) a locus of familiarity and constancy, iv) a place of retreat, $v$ ) a repository of memories of life history, vi) a site of the expression of personal interests and values, and vii) a site of the expression of functional competence and 
engagement in meaningful activities. They also identified that treasured personal possessions indicated emotional attachment to home and personal interests, values and life histories. As such, Soilemezi et al. (2017) claimed that it was all these important meanings that stimulated people living with dementia to view leaving their home, or to go in to care, as a 'death sentence'. The significant meanings of home and cherished possessions are echoed by Li et al. (2019) that revealed that home captured life stories and presented aspects of the self through the assignation of specific meanings to the home and home objects.

However, the onset and progression of dementia changed the meaning and experiences of living at home as the environment became more challenging (Soilemezi et al., 2017; Lloyd \& Stirling, 2015; Li et al., 2019). Living at home might provoke a series of tensions and discontinuity between safety and comfort, familiarity and adaptations, and risks and independence (Soilemezi et al., 2017; Li et al., 2019). In addition, changes in autonomy modified the socio-spatial boundaries at home which re-defined the meaning of home (Lloyd $\&$ Stirling, 2015). This phenomenon was observed when service workers entered the home and people living with dementia were often not alarmed by these "normative boundary breaches' but were, instead, concerned by their capacity to control the physical and social distance between themselves and visitors, leading to a sense of spatial constriction:

I sometimes get a bit crushed in sometimes with people... It's sort of an intermittent thing that sort of comes and goes. Sometimes I feel as though I'm hemmed-in in a situation, so I don't particularly like it, but some things have got to be done and I can do that. But I like a bit of quiet. (Person living with dementia; Lloyd \& Stirling, 2015, p.1811)

\section{$\underline{\text { Home modification and adaptation }}$}

People living with dementia used various methods to modify their home and to overcome environmental challenges (Górska et al., 2017; Li et al., 2019; Soilemezi et al., 2017), so that they could maintain a sense of control and continuity in everyday living. Relocation was one of the methods used to proactively change the home environment, hence maintaining autonomy and independence, and gaining better support, even though relocation might be at the expense of connecting with social ties ( $\mathrm{Li}$ et al., 2019). In addition, effective application of useful components was used to make life with dementia at home much easier, such as 
through a better layout and design to enable easier navigation through the home (Górska et al., 2017; Li et al., 2019; Soilemezi et al., 2017). Moreover, the home space and objects could be adjusted in various ways (e.g. by creating wider doorways, repositioning objects and furniture, and altering shower rooms) to provide space, supervision and comfort (Górska et al., 2017; Soilemezi et al., 2017). Finally, seeking and using resources (e.g. assistive devices and equipment, carers who are able to create therapeutic possibilities in the home) were found to enhance independent living and offered a sense of safety and security to people living with dementia (Górska et al., 2017; Soilemezi et al., 2017).

\section{$\underline{\text { Home-neighbourhood connection }}$}

Common features of the home, e.g. windows and the garden, connected private places to public spaces, captured life stories and held specific meanings (Li et al., 2019; Ward et al., 2018). Windows were not something to simply look through but, instead, served as a connection between indoor and outdoor spaces and enabled people living with dementia to remotely engage with the outside world where they could no longer physically connected to (Li et al., 2019; Ward et al., 2018). As an illustration, a person living alone with dementia in an apartment near the city centre watched events on the street via her window, as she shared:

I spend many an hour sat in my chair watching a fella that works there and honest to god if I ever needed a man to work for me it would be him. He never stops, it's the best worker I've ever seen, he has nobody watching him but what he hasn't done... he's painted that building a couple of times and he's redone the floor, I've never seen anybody work like him. So it fascinates me watching him through window. (Ward et al., 2018, p.6)

The garden at home was also identified as a significant place where people living with dementia had a physical and emotional investment, gained enjoyment, and provided a sense of connection from inside to outside the home ( $\mathrm{Li}$ et al., 2019). In the garden, people living with dementia carried out activities such as gardening, sitting and relaxing, looking around the garden and its various features, and interacting with family members. These place-making processes had a positive impact upon people living with dementia who felt happier, more relaxed and at peace with themselves (Li et al., 2019). 


\section{Theme 2: Social interactions}

Analysis of 11 studies revealed that interaction with social ties enabled people living with dementia to actively construct their social environment, ranged across spousal carers, family, friends, neighbours and care professionals. The experience of such interaction influenced personhood and relational citizenship, particularly through everyday communication and processes of engagement.

\section{Interacting with the spouse and family members}

A couple's relationships affected their bonds and abilities to face and live with dementia but, more importantly, impacted upon people living with dementia's independence, dignity, selfesteem, social connections and health (Johnston \& Terp, 2015; Li et al., 2019; Ruthirakuhan et al., 2012; Tranvåg et al., 2014; Wiersma et al., 2016). Tranvåg et al. (2014) interviewed 11 people with mild to moderate dementia living in their own home and found dignitypreserving could be strengthened through experiencing the spouse's affection, joy and love whilst gaining spousal support during activities of daily living, as shared by a person living with dementia:

My wife ... not just the fact that she helps me prepare my meals ... there's so much more than that ... it's the depth of dignity, joy and love ... which means so much ... and defines what dignity really is ... (p.582)

In addition, Li et al. (2019) observed that a couple's relationship had an impact within and beyond the two persons and particularly influenced the person living with dementia's daily experience and connection to their neighbourhood. The key to this effect was a sense of resilience and togetherness, with the couple constantly navigating and negotiating their role whilst retaining a close bond when going through the unknown journey of dementia. As an illustration from this study, a person living with dementia took on a caring role during, and after, his partner's bowel cancer operation. Within this relational context, the person living with dementia was not simply a care-recipient but, instead, an active contributor to the caring and relational dynamic. 
In terms of family cohesion, close bonds (characterised by mutual affection, trust, respect and appreciation) sustained personhood whereas reluctant helping or task-centred relationships diminished personhood (Smebye \& Kirkewold, 2013; Tranvåg et al., 2014). For example, in the study by Smebye and Kirkewold (2013), a daughter's presence made the person living with dementia feel secure, as illustrated below:

Not long ago I fetched her because I was taking her to the doctor, and she is sitting there (in the car) and she says: "K." I answered: "Yes." and she continued: "Is it you?" I believe she knows there is something familiar about me and she feels secure when I am around. (p5)

\section{Interacting with friends and neighbours}

When expanding engagement to wider social networks, e.g. friends and neighbours, interactions again influenced dignity, self-esteem, connectedness and activities of daily living (Górska et al., 2017; Ward et al., 2018; Ruthirakuham et al., 2012; Tranvåg et al., 2014; Wiersma \& Denton, 2016; Wolverson et al., 2016). Here, Tranvåg et al. (2014) argued that keeping in touch with long-term friends and experiencing social inclusion as an active member, were a crucial source for dignity preservation for people living with dementia:

What gives my life dignity?...having friends, both men and women ... keeping our friendships alive, and enjoying time together... they (social network) treat me as a normal person [...] not everyone makes a big deal out of my diagnosis, and luckily for that [...] as far as dementia is concerned people should be very careful ... and not limit their focus ... to the diagnosis alone. (Person living with dementia, p.583)

However, Górska et al. (2017) pointed out that challenges in social engagement were caused by decreasing communication, interaction skills and changes in other people's attitudes towards dementia; consequently, people living with dementia might feel inadequate and ashamed, ultimately avoiding or withdrawing from social engagement:

In my whole life I have been active in many choirs. Now, when I no longer remember the songs, I have decided to give up that activity ... not funny to do things bad when you have been a "master". (Person living with dementia; p.184) 
I sometimes find it difficult to express myself, I cannot find the words, and therefore I avoid talking to others. (Person living with dementia; p.185)

Despite this, striving for continuity in social participation and connection was a significant feature in maintaining a sense of self and in endorsing personal biographies (Górska et al., 2018; Li et al., 2019). Continuity in socialisation could be nurtured through a safe, supportive environment where reciprocity was a key feature of the neighbourhood (Li et al., 2019; Ward et al., 2018; Wiersma \& Denton, 2016; Wiersma et al., 2016).

\section{$\underline{\text { Interacting with care professionals }}$}

The literature highlighted that people living with dementia's relationships with care professionals affected their sense of personhood and dignity. Professional relationships, where professionals treated people living with dementia with respect and kindness, and promoted agency and retained abilities, resulted in sustaining personhood and preserving dignity (Smebye \& Kirkewold, 2013; Tranvåg et al., 2014). For example, feeling respected, listened to, and taken seriously by healthcare professionals significantly impacted upon people living with dementia's self-perception and dignity (Tranvåg et al., 2014). In contrast, 'unprofessional' relationships, where professionals were friendly and polite but perceived their work as a job that had to be done, diminished personhood and dignity (Smebye \& Kirkewold, 2013; Tranvåg et al., 2014), as shown in the data extract:

... be concerned about what you have to say [... ] be treated as a real person ... and allowed to be the centre of attention (of the Health Care Professionals) ... and encouraged to express your concerns ... and be listened to ... yes, because there are many times one is not allowed to do so ... when those you meet don't acknowledge you as an equal ... making you feel small and unimportant [... ] when they are superficial ... I can feel the difference ... sensing that what you have to say is of real interest, yes ... yes, that makes a great difference. (Person living with dementia; Trånvag et al., 2014, p.584) 


\section{Theme 3: Activities}

The theme of 'activities' emerged from 22 studies, with the sub-themes being 'physical activities' and 'meaningful activities'. Engaging in activities provided opportunities in which people living with dementia were supported; so that they could connect to places outside the home and to socialise with others, ultimately gaining numerous benefits, including a sense of neighbourhood connectedness. People living with dementia's regular connections with physical and social environments through activities were crucial in constructing their own neighbourhood and in affecting their health, particularly social health over time.

\section{$\underline{\text { Physical activities }}$}

'Physical activities' included various types of exercises, such as swimming, golf, Tai Chi and walking. Within an inclusive and supportive atmosphere, people living with dementia who engaged in such activities could gain health-related benefits, particularly social health benefits (Bowes et al., 2013; Karania 2017; Malthouse \& Fox, 2014; Mapes, 2018; Wright, 2016). At an individual level, participating in physical activities improved behaviour (e.g. improved sleeping and engagement in activities, increased mobility, reduced falls and wandering behaviour, and engaged in healthier living), cognition (e.g. improved scores on cognitive tests) and function (e.g. improvements in body strength and flexibility, and better balance). Involvement in physical activities also provided psychological benefits, such as improved physiological outcomes, positive effect on mood and freedom, gained a sense of continuity in past activities that were enjoyable, increased self-esteem, increased social connectedness and enhanced well-being and quality of life (Bowes et al., 2013; Karania 2017; Malthouse \& Fox, 2014; Mapes, 2018; Wright, 2016). Some of these physical activityrelated benefits could be seen via the following data extracts from persons with Alzheimer's disease in Malthouse and Fox's study (2014):

I don't tend to do things like I used to, you know, I kind of just went down a shop, those are the things I miss most of all ... Just to do what I want to so, when I want to do it. I want to do things I want to do myself, on my own personally, than be, you know, be guided by someone who says you have to do this. (p.171) 
The lady who has the class is delightful and she's brilliant. . after having had a yoga session, I feel as though I'm on cloud nine. (p.172)

At an interpersonal level, taking part in physical activities particularly improved social health through making connections with others who shared similar experiences, through the context for non-verbal communications and through expressing a sense of self and identity, so eventually enhanced quality of life (Wright, 2016). For instance, a 76-year-old woman living with dementia recognised this when she communicated with others through gesture: "when you wave to somebody at the other side [of the café]. There's ways and means ... [of communicating] ... instead of just talking to people, isn't there?”'(Wright, 2016, p.531). Another example is that an 85-year-old woman living with dementia was unable to talk to others, however, with the assistance of volunteers, dancing allowed her to initiate social contact and shared an activity with others. This was detailed by Wright (2016) in the fieldnote:

Megan is gently led onto the dance floor by two volunteers. She looks lost but her calm expression suggests that she is comfortable with being here. Megan smiles as she starts to move her body gracefully to the music. She joins a circle of others and her smile broadens. She looks across the hall in my direction and beckons me to join her. (p. 532)

At a broader social environmental level, engaging in physical activities enhanced socialisation, self-esteem and confidence, and gained positive emotional impacts, such as pleasure and enjoyment (Bowes et al., 2013; Malthouse \& Fox, 2014; Wright, 2016). As an illustration, a 75-year-old woman described how she looked forward to activities at the day centre: "I enjoy everything here... when I leave at the end of one week I can't wait to come again." (Wright, 2016, p.528).

\section{$\underline{\text { Meaningful activities }}$}

According to this review, 'meaningful activities' referred to activities that required engagement in intellectual stimulation, socialisation and/or personal biographical interests. These activities covered leisure-based activities, memory and/or cognition related engagement and tourism. Within a supportive environment, participation in various leisurebased activities (e.g. singing, drama therapy, and art viewing and making) had a positive 
impact upon memory and cognitive functioning, self-esteem and socialisation, and facilitated social participation and contribution (Camic et al., 2013; Jaaniste et al., 2015; Osman et al., 2016). As an illustration, singing was evident in bringing benefits to people living with dementia (Camic et al., 2013; Osman et al., 2016). At an individual level, singing positively influenced memory and lifted the spirits, sometimes changing beliefs about self and attitude towards acceptance of the diagnosis, whereas at an interpersonal level, singing together supported social inclusion and provided a mutual, shared, enjoyable experience for people living with dementia and their carers. This dynamic is neatly summarised in the study by Camic et al. (2013): "I think singing is a lovely way of relaxing. . everybody joined in" (person living with dementia; p.167).

Engaging in activities that stimulated memory and/or cognition (e.g. cognitive stimulation programme, sporting memories work, and memory booster social club) fulfilled the need for active lifestyles, promoted shared experiences, and enhanced social inclusion (Clark, Murphy, Jameson-Allen, \& Wilkins, 2015; Fortune \& McKeown, 2016; Tuppen, 2012). By way of an illustration, participation in a 'Memory Booster Social Club' provided an opportunity for people living with early dementia to connect with others on a shared journey within a safe space: "the social aspect is the most important part" (p. 381), thereby gaining a sense of inclusion and belonging within, and beyond, the group (Fortune \& McKeown, 2016).

Findings from the studies also revealed that meaningful activities included community engagement, such as football club (Carone et al., 2014), walking programme (Phinney et al., 2016) and gardening programme (Hewitt et al., 2013) and participation in service design (Mayrhofer et al., 2017). For instance, Phinney et al. (2016) claimed that regular engagement in a neighbourhood walking programme offered people living with young-onset dementia an opportunity to have enjoyable experiences, to gain a sense of social belonging through a 'non-medicalised atmosphere', to 'claim a place in the community', and to focus on 'normal everyday activities'. A care partner shared her views about the programme as: "A place that said, 'we're living, we're living, we are here because we are alive, and we're going to have fun, and that's going to be the rest of my life, just to enjoy every minute...", (p.11) 
In terms of participation in service design, Mayrhofer et al. (2017) systematically reviewed 20 articles and found four publications that reported on how people with young-onset dementia could contribute to service design by their involvement in a project steering group. They also identified two articles that highlighted how people with young-onset dementia's active participation influenced the design of individualised support, which in turn increased self-esteem and social inclusion as well as a sense of citizenship.

\section{Theme 4: Transportation}

The theme of 'transportation' emerged from five studies, highlighting driving cessation increased road safety, yet it was associated with the loss of identity, self-worth, access to places and community engagement (Andrew, Traynor, \& Iverson, 2015; Carmody, Traynor, \& Iverson, 2012; Liddle, Allen, Bennett, \& Lie, 2013), ultimately leading to a 'shrinking world'.

When driving cessation became inevitable, attention should be paid to 'the depth of losses to identity, community engagement, and household access' as during the post-cessation stage, a smaller world with a reduced geographical area and limited activities would be the perception and reality (Liddle et al., 2013). For instance, Liddle et al. (2013) interviewed four retired drivers living with dementia, 11 family member and 15 health professionals to understand the processes of driving cessation for people living with dementia. In their research, a daughter expressed concern about the isolated situation for her mother who lived with dementia and stopped driving: "[Mom] couldn't drive herself and nobody else did it” (p.2040). The importance of driving could also be highlighted by another daughter's description of her father: "to Dad, having a car was absolutely everything" (p.2037) and "it meant transport, it meant independence, but it was also something about the activity itself that was so important to him... It was his manly activity” (p.2038).

Following driving cessation, providing better alternative transportation and community support were crucial to facilitate accessibility and social engagement out of the home (Andrew et al., 2015; Carmody et al., 2012; Liddle et al., 2013; Risser et al., 2015). However, alternatives were often described as an unmet need by people living with dementia and in particular public transport was identified as a real issue (Liddle et al., 2013; Innes, Page, \& Cutler, 2016). By way of illustration, Innes et al. (2016) addressed the research question: 
what are the barriers to leisure participation experienced by households affected by dementia? by carrying out five focus groups with 16 persons living with dementia and 32 (family) carers. They found that alternative modes of transport to replace the car were challenging so that their accessibility to outdoor places and their participation in leisure activities were restricted, as shown in one participant's description:

We find it very difficult because we don't have a car, and transport is a real problem. I mean we like to go to Poole but can't get there on public transport. So, a lot of tourist places are closed to use really. (p. 1652)

In response to the issues relating to public transport, relevant solutions were proposed for people with cognitive impairments, including dementia, by Risser et al. (2013). The solutions aimed to stress the need for reliable information before/during the trip, accessible/barrier-free pedestrian environment, good design for terminals and bus stops, security, safety and trained personnel, a transport chain for carrying out trips from door-to-door, and accessible public transport.

Additionally, limited community support options were highlighted, raising the requirement for, but not limited to, educational programmes, reliable sources of information, support for caregivers, and reflection and reminiscence for people living with dementia who were encountering driving cessation (Andrew et al., 2015; Carmody et al., 2012; Liddle et al., 2013). For instance, Andrew et al. (2015) conducted an integrative review of 43 articles. They were supportive of the efficacy of educational programmes, with timely access to information, to inform drivers living with dementia about the potential impact upon capacity to drive safely and advocated an 'involved' strategy by engaging the drivers living with dementia who were facing decisions about driving retirement.

Although driving cessation was unavoidable, the post-retirement journey required an inclusive and supportive environment to facilitate a smooth transition process. In parallel, alternative options should be offered to enable those who gave up driving to continue to access outdoor places and engage in activities, so that the potential for a 'shrinking world' could be delayed. 


\section{Discussion}

This review analysed 44 publications relating to neighbourhoods and dementia. The principal findings showed that a neighbourhood was a lived, connected place with a variation in its geographical boundary. The 'connected neighbourhood' was constituted through the interaction of people living with dementia as active 'place-makers' and their neighbourhood as both physical and social environments. These insights support a 'bottom-up', strengthbased approach to neighbourhood meaning and construction, and give additional meaning to the global concept of dementia-friendly communities. The findings also help address the knowledge gap, "no research that sets out to enquire how people with dementia might define their neighbourhood" (Keady et al., 2012, p.11).

The new understanding of neighbourhood draws attention to personal interpretation of 'being in place' within a fluid geographical boundary and reinforces Breakwell's (1986) argument that a place is not necessarily a product of geographical hierarchy. The findings also support Conradson's (2005) claim, “interactions between people and environment are complex and multifaceted, emerging out of particular embodied encounters but are also subject to later interpretation" (p. 2). However, the new insights into 'neighbourhood' meanings challenge Blackman's (2006) definition of a neighbourhood being 'a walkable zone of experience' at the "smallest significant socio-spatial scale of the societies of which they are part" (p.2). His claim seems to neglect a wider view of the area outside of this 'walkable zone' and gives little credence to the importance of the social environment.

By applying a social model of disability to dementia, this review outlined the dynamic, multilayered, person-neighbourhood relationships that existed in everyday life. Various neighbourhood components influenced people living with dementia's everyday experiences; conversely, people could use their strengths and abilities to improve their living experiences and to make their own sense of places. This new knowledge echoes Lawton's (1998) view of the person-environment relationship from an 'interactional' perspective:

"Although person and environment form a unified system where what is inside is philosophically inseparable from what is outside, for heuristic purposes, it is necessary to speak of, and attempt to measure, them separately" (p. 1). 
In addition, the findings highlighted that the dynamic relationship between people living with dementia and their neighbourhood impacted upon their health and particularly social health. This underpins the existing knowledge relating to the human-environment relationship that closely associates with health and well-being in old age (Wahl \& Weisman, 2003; Gomez et al., 2010).

The findings also indicated that home was a significant place which captured important life histories and represented aspects of self. The meaning of home for people living with dementia echoes Rowles and Bernard's (2013) claim that home was where living became active and had both meaning and attachment for the person, and this space could be seen as part of identity. According to our review, although people living with dementia employed various strategies to ease their experience of living at home and to exercise control over the space, the progression of the condition would eventually change the meaning of home, potentially leading to a feeling of 'homelessness' (Soilemezi et al., 2017; Lloyd \& Stirling, 2015; Li et al., 2019). As such, a pressing need in dementia studies is raised to better understand what people living with dementia think is important when living at home and, more crucially, when a sense of being at home is challenged. It might be worth looking beyond the service-oriented functionalist approaches to maintaining a person at home whilst considering the fluid meaning and experience of the place for those living with dementia.

In terms of 'transportation', despite the inadequate studies identified, better support and alternative transport are urgently needed to minimise the negative impact of driving cessation on the everyday lives of drivers who live with dementia and consequently have to stop driving for road safety. Indeed, the absence of adequate alternative transportation services is also highlighted by Rosenbloom and Herbel's work (2009) and by the AARP Public Policy Institute (2005) that argued for the development of multiple transportation services and alternative options. The lack of evidence on transportation in this review resonates with Keady et al.'s (2012) review where limited evidence on public transport being a significant issue was identified.

In this review, we used a realist review method with GRADE-CERQual. The realist review method helped to identify which findings would be more relevant to the local dementia population within a specific context. For GRADE-CERQual assessment, 'high confidence' 
indicates that it is highly likely that the review finding is a reasonable presentation of the phenomenon of interest, whilst 'very low confidence' presents that it is not clear that the review findings is a reasonable representation of the phenomenon of interest. This does not mean that there is no value in the 'very low confidence' findings, but instead, careful interpretation is needed based on the reasons given for the findings. Hence, we believe that the realist review method with GRADE-Qual would assist policymakers in deciding which findings would be more appropriate to guide local dementia care in context-specific situations. In addition, the findings from this qualitative evidence synthesis provided rich insights into the lived experience of people with dementia, thereby enhancing the transferability of the review findings to a population within similar situations where analogous events arise (Yin, 2010).

We have identified several limitations in this review. First, given the large number of included articles, in-depth discussions might be lacking due to the limited space available for this article. The selected papers also suggests that the overall perception and the neighbourhood-dementia nexus were captured via our approach to the 10 databases, even though we do appreciate that some knowledge gaps exist and deserve further attention. Second, we only found 11 articles that focused upon people with young-onset dementia, with no evidence on their definition of a neighbourhood. Third, we did not include studies conducted in care home settings; however, we do acknowledge the close association between such settings and neighbourhoods and argue for a separate focus to explore such an association. Finally, we were not intending to compare the lived experience of people with dementia across areas (such as rural versus urban) and countries and evidence on rural areas (where reported, only three primary studies were conducted in rural areas and three in a combination of rural and urban areas) was limited. In fact, we do appreciate where people with dementia live affects their perceptions of neighbourhood and recommend further research to investigate how different environmental factors might influence their lived experience, with the priorities being considered for areas that could be potentially addressed in practice. 


\section{Conclusion and future research directions}

This review has explored a contemporary understanding of neighbourhoods and dementia, and detailed how people living with dementia, place and health were linked via an ongoing intertwined process. This review has also highlighted the active role of people living with dementia as place-makers within a neighbourhood context, so harnessing the strength-based approach in dementia research.

The increasing interest in dementia and neighbourhood has led to a growing take-up of research and facilitated the emergence of dementia studies across fields. However, looking ahead, further research is warranted to explore neighbourhoods and dementia at a larger scale with the lens of the social model of disability. Such research could be more beneficial when using innovative, participatory methods as people living with dementia indeed demonstrated their strength and abilities in contributing to society. Moreover, attention to diversity and the need to consider care homes and dialogue between age-friendly and dementia-friendly perspectives are encouraged in further studies. Finally, it would be beneficial to focus upon social inclusion and dementia across various community-based services and organisations to further understand the interconnections between people, care and health at a neighbourhood level, preferably separating rural and urban areas.

Ethical approval and patient consent: Not applicable.

Funding: This research received no specific grant from any funding agency in the public, commercial, or not-for-profit sectors.

Declaration of conflicting interests: The authors declare that there is no conflict of interest.

\section{References}

AARP Public Policy Institute. (2005). Livable communities: An evaluation guide. Washington, DC: AARP.

Alzheimer's Society. (2014). Dementia 2014: Opportunity for change. London, England: Author. 
Alzheimer's Society. (2017). What is dementia? London, England: Author.

Alzheimer's Disease International. (2009). World Alzheimer Report 2009. London, England: Author

Alzheimer's Disease International (2015). The global impact of dementia: An analysis of prevalence, incidence, cost and trends. London, England: Author.

Andrew, C., Traynor, V., \& Iverson, D. (2015). An integrative review: understanding driving retirement decisions for individuals livign with a dementia. Informing practice and Policy Worldwide through Research and Scholarship, DOI: 10.1111/jan.12727

Bartlett, R., \& O'Connor, D. (2007). From personhood to citizenship: broadening the lens for dementia practice and research. J Aging Studies, 21: 107-18.

Bartlett, R., \& O’Connor, D. (2010). Broadening the Dementia Debate: Towards social citizenship. Bristol: The Policy Press.

Blackman, T. (2006). Placing Health: Neighbourhood Renewal, Health Improvement and Complexity. Bristol, England: The Policy Press.

Bowes, A., Dawson, A., Jepson, R., \& McCabe, L. (2013). Physical activity for people with dementia: a scoping study. BMC Geriatrics, 13(129).

Brock, P. (2008). Community: the structure of belonging. San Francisco, CA: Berrett-Koehler Publishers.

Calvert, L., Keady, J., Khetani, B., Riley, C., Open Doors Research Group, \& Swarbrick, C. (2020). ' . . . this is my home and my neighbourhood with my very good and not so good memories': The story of autobiographical place-making and a recent life with dementia. Special edition 'People Living with Dementia' (Guest edited by Open Doors and Caroline Swarbrick). Dementia: the international journal of social research and practice, 19(1), 111-128. DOI: 10.1177/1471301219873524

Camic, P. M., Williams, C. M., \& Meeten, F. (2013). Does a 'singing together group' improve the quality of life of people with a dementia and their carers? A pilot evaluation study. Dementia, 12(2), 157-176. DOI: 10.1177/1471301211422761

Camic, P. M., Tischler, V., \& Pearman, C. H. (2014). Viewing and making art together: a multi-session art-gallery-based intervention for people with dementia and their carers. Aging \& Mental Health, 18(2), 161-168. http://dx.doi.org/10.1080/13607863.2013.818101

Carmody, J., Traynor, V., \& Iverson, D. C. (2012). Dementia and driving: An approach for general practice. Australian Family Physician, 41(4), 230-233.

Carone, L., Tischler, V., \& Dening, T. (2014). Football and dementia: A qualitative investigation of a community based sports group for men with early onset dementia. Dementia, DOI: $10.1177 / 1471301214560239$

Chaplin, R., \& Davidson, I. (2016). What are the experiences of people with dementia in employment? Dementia (London), 15(2), 147-161. ISSN 1741-2684. 
Clark, M., Murphy, C., Jameson-Allen, T., \& Wilkins, C. (2015). Sporting memories \& the social inclusion of older people experiencing mental health problems. Mental Health and Social Inclusion, 19(4), 202-211. DOI: 10.1108/MHSI-06-2015-0024

Conradson, D. (2005). Landscape, care and the relational self: Therapeutic encounters in rural England. Health and Place. 11, 337-348. doi:10.1016/j.healthplace.2005.02.004.

Crampton, J., Dean, J., \& Eley, R. (2012). Creating a dementia-friendly York. York, England: Joseph Rowntree Foundation.

Critical Appraisal Skills Programme. (2018). CASP Checklists. Oxford. Retrieved from https://casp-uk.net/casp-tools-checklists/

Department of Health. (2015). Prime Minister's challenge on dementia 2020. London, England: Author.

Douglas, H. (2010). Types of community. In H. Anheier \& S. Toepler (Eds.), International Encyclopedia of Civil Society (pp. 539-544). Springer.

Fortune, D., \& McKeown, J. (2016). Sharing the journey: Exploring a social leisure program for persons with dementia and their spouses. Leisure Sciences, 38(40), 373-387. http://dx.doi.org/10.1081/01490400.2016.1157776

Gibson, G., Dickinson, C., Brittain, K., \& Robinson, L. (2015). The everyday use of assistive technology by people with dementia and their family carers: a qualitative study. $B M C$ Geriatrics, DOI: 10.1186/s12877-015-0091-3

Gomez, L., Parra, D., Buchner, D., Brownson, R., Sarmiento, O., Pinzon, J., . . \& Lobelo, F. (2010). Built environment attributes and walking patterns among the elderly population in Bogota. American Journal of Preventive Medicine, 592-599.

Górska, S., Forsyth, K., \& Maciver, D. (2018). Living with dementia: A meta-synthesis of qualitative research on the lived experience. The Gerontologist, 58, 180-196. DOI: 10.1093/geront/gnw195

GRADE-CERQual (2018). Confidence in the evidence from reviews of qualitative research. https://www.cerqual.org/what-is-the-grade-cerqual-approach2/

Gusfield, J. R. (1975). The (F)Utility of Knowledge? The Relation of Social Science to Public Policy toward Drugs. The ANNALS of the American Academy of Political and Social Science, 417(1): 1-15. doi:10.1177/000271627541700102

Guyatt, G., Oxman, A.D., Akl, E.A., Kunz, R., Vist, G., Brozek, J., Norris, S., Falck-Ytter, Y., Glasziou, P., deBeer, H., Jaeschke, R., Rind, D., Meerpohl, J., Dahm, P., \& Schunemann, H.J. (2011). GRADE guidelines: 1. Introcution - GRADE evidence profiles and summary of findings tables. Journal of Clinical Epidemiology, 64: 383394. doi: 10.1016/j.jclinepi.2010.04.026

Hewitt, P., Watts, C., Hussey, J., Thrive, K. P., \& Williams, T. I. (2013). Does a structured gardening programme improve well-being in young-onset dementia? A preliminary study. DOI: $10.4276 / 030802213 X 13757040168270$ 
Huber, M., Knottnerus, J. A., Green, L., van der Horst, H., Jadad, A. R., Kromhout, D., Leonard, B., \& Smid, H. (2011). How should we define health? BMJ, 343, d4163. DOI: $10.1136 / \mathrm{bmj} . \mathrm{d} 4163$

Innes, A., Page, S. J., \& Cutler, C. (2016). Barriers to leisure participation for people with dementia and their carers: An exploratory analysis of carer and people with dementia's experiences. Dementia, 15(6), 1643-1665. DOI: 10.1177/1471301215570346

Jaaniste, J., Linnell, S., Ollerton, R.L., \& Slewa-Younan, S. (2015). The Arts in Psychotherapy, 43, 40-48. http://dx.doi.org/10.1016/j.aip.2014.12.010

Johnston, L., \& Terp, D. M. (2015). Dynamics in couples facing early Alzheimer's disease. Clinical Gerontologist, 38, 283-301. DOI: 10.1080/07317115.2015.1032465

Keady, J., Campbell, S., Barnes, H., Ward, R., Li, X., Swarbrick, C., Burrow, S., \& Elvish, R. (2012). Neighbourhoods and dementia in the health and social care context: a realist review of the literature and implications for UK policy development. Reviews in Clinical Gerontology, 22, 150-163.

La Gory, M., Ward, R., \& Sherman, S. (1985). The ecology of ageing: Neighbourhood satisfaction in an older population. The sociological quarterly, 26(3), 405-418. DOI: $10.1111 / \mathrm{j} .1533-8525.1985 . t b 00235 . \mathrm{x}$

Lawton, M. P. (1998). Environment and ageing: Theory revisited. In R. J. Scheidt \& P. G. Windley (Eds.), Environemnt and ageing theory: A focus on housing (pp. 1-31). Westport, CT: Greenwood Press.

Lewin, S., Booth, A., Glenton, C., Munthe-Kaas, H., Rashidian, A., Wainwright, M., Bohren M.A., Tunçalp, Ö., Colvin C.J., Garside, R., Carlsen, B., Langlois, E.V., \& Noyes., J. (2018). Applying GRADE-CERQual to qualitative evidence synthesis findings: introduction to the series. Implementation Science, 13(Suppl 1): 2. DOI: 10.1186/s13012-017-0688-3

Li, X., Keady, J., \& Ward, R. (2019). Transforming lived places into the connected neighbourhood: a longitudinal narrative study of five couples where one partner has an early diagnosis of dementia. Ageing \& Society. https://doi.org/10.1017/S0144686X1900117X

Liddle, J., Bennett, S., Allen, S., Lie, D. C., Standen, B., \& Pachana, N. A. (2013). The stages of driving cessation for people with dementia: needs and challenges. International Psychogeriatrics, 25(12). 2033-2046. DOI: 10.1017/S1041610213001464

Lloyd, B. T., \& Stirling, C. (2015). The will to mobility: life-space satisfaction and distress in people with dementia who live alone. Ageing \& Society, 35, 1801-1820. DOI: $10.1017 / \mathrm{S} 0144686 \mathrm{X} 14000683$.

Malthouse, R., \& Fox, F. (2014). Exploring experiences of physical activity among people with Alzheimer's disease and their spouse carers: a qualitative study. Physiotherapy, 100, 169-175. DOI: 10.1016/j.physio.2013.10.002

Massey, D. (1994). Space, place and gender. US: University of Minnesota Press. 
Mapes, N. (2017). Think outside: positive risk-taking with people living with dementia. Working with Older People, 21(3), 157-166. DOI:10.1108/WWOP-03-2017-0007.

Mayrhofer, A., Mathie, E., McKeown, J., Bunn, F., \& Goodman, C. (2017). Age-appropriate services for people diagnosed with young onset dementia: a systematic review. Aging \& Mental Health, 22(8), 933-941. DOI: 10.1080/13607863.2017.1334038.

McCulloch, S., Robertson, D., \& Kirkpatrick, P. (2016). Sustaining people with dementia or mild cognitive impairment in employment: A systematic review of qualitative evidence. British Journal of Occupational Therapy, 79(11), 682-692. DOI: $10.1177 / 0308022616665402$

Mental Health Foundation. (2015). Dementia, rights, and the social model of disability: A new direction for policy and practice? London, England: Author.

Mitchell, L. (2012). Breaking new ground: The quest for dementia friendly communities. Housing Leaning \& Improvement Network, London.

Mitchell, L., \& Burton, E. (2010). Designing dementia-friendly neighbourhoods: Helping people with dementia to get out and about. Journal of Integrated Care, 18(6), 11-18. DOI: $10.5042 /$ jic. 2010.0647

O’Campo, P., Kirst, M., Schaefer-McDaniel, N., Firestone, M., Scott, A., \& McShane, K. (2009). Community-based services for homeless adults experiencing concurrent mental health and substance use disorders: a realist approach to synthesizing evidence. J Urban Health Bulletin NY Acad Med, 86, 965-89.

Odzakovic, E., Hellström, I., Ward, R., \& Kullberg, A. (2018), 'Overjoyed that I can go outside': Using walking interviews to learn about the lived experience and meaning of neighbourhood for people living with dementia. Dementia, 1471301218817453. https://doi.org/10.1177/1471301218817453

Oliver, M., Sapey, B., \& Thomas, P. (2012). Social work with disabled people. NY: Palgrave.

Osman, S. E., Tischler, V., \& Schneider, J. (2016). 'Singing for the brain': A qualitative study exploring the health and well-being benefits of singing for people with dementia and their carers. Dementia, 15(6), 1326-1339. DOI: 10.1177/1471301214556291

Owen, N., Cerin, E., Leslie, E., duToit, L., Coffee, N., Frank, L., . . \& S Sallis, J. (2007). Neighbourhood walkability and the walking behaviour of Australian adults. American Journal of Preventive Medicine, 387-395.

Patton, M.Q. (1999). Enhancing the quality and credibility of qualitative analysis. Health Services Research, 34(5). Part II. 1189-1208.

Pawson, R., Greenhalgh, P., Harvey, G., \& Walshe, K. (2005). Realist review - a new method of systematic review designed for complex policy interventions. $J$ Health Services Res Policy, 10 (suppl 1), 21-34.

Phinney, A., Kelson, E., Baumbusch, J., O’Connor, D., \& Purves, B. (2016). Walking in the neighbourhood: Performing social citizenship in dementia. Dementia, 15(3), 381-394. DOI: $10.1177 / 1471301216638180$ 
Prior, D., Stewart, J., \& Walsh, K. (1995). Citizenship: rights, community and participation. London, England: Pitman.

Rabanal, L.I., Chatwin, J., Walker, A., O'Sullivan, M., \& Williamson, T. (2018). Understanding the needs and experiences of people with young onset dementia: a qualitative study. BMJ Open, 8:e021166. DOI:10.1136/bmjopen-2017-021166.

Richardson, A., Pedley, G., Pelone, F., Akhtar, F., Chang, J., Muleya, W., \& Greenwood, N. (2016). Psychosocial interventions for people with young onset dementia and their carers: a systematic review. Internaitonal Psychogeriatrics, 28(9), 1441-1454. DOI:10.1017/S1041610216000132.

Risser, R., Månsson Lexell, E., Bell, D., Iwarsson, S., \& Ståhl, A. (2015). Use of local public transport among people with cognitive impairments - A literature review.

Transportation Research. Part F: Traffic Psychology and Behaviour, 29, 83-97. DOI: 10.1016/j.trf.2015.01.002

Roach, P., \& Drummond, N. (2014). 'It's nice to have something to do': early-onset dementia and maintaining purposeful activity. Journal of Psychiatric and Mental Health Nursing, 21, 889-895.

Roach, P., Drummond, N., \& Keady, J. (2016). 'Nobody would say that it is Alzheimer's or dementia at this age': Family adjustment following a diagnosis of early-onset dementia. Journal of aging studies, 36, 26-32.

Rosenbloom, S., \& Herbel, S. (2009). The safety and mobility patterns of older women: Do current patterns foretell the future? Public Works Management \& Policy, 13(4), 338353. DOI: $10.1177 / 1087724 X 09334496$

Rowles, G., \& Bernard, M. (2013). Environmental gerontology: making meaningful places in old age. New York, NY: Springer.

Ruthirakuhan, M., Luedke, A.C., Tam, A., Goel, A., Kurji, A., \& Garcia, A. (2012). Use of physical and intellectual activites and socialisation in the management of cognitve decline of aging and in dementia: A review. Journal of Aging Research, 2012, Article ID 384875. http://dx.doi.org/10.1155/2012/384875

Samsi, K., \& Manthorpe, J. (2013). Everyday decision-making in dementia: findings from a longitudinal interview study of people with dementia and family carers. International Psychogeriatrics, 25(6), 949-961. DOI: 10.1017/S1041610213000306

Satariano, W. (2006). Ageing, health, and the environment: An ecological model. In W. Satariano (Ed.), Epidemiology of Ageing: An Ecological Approach (pp. 39-84). Berkeley, CA: Jones and Bartlett.

Smebye, K.L., \& Kirkewold, M. (2013). The influence of relationships on personhood in dementia care: a qualitative, hermeneutic study. BMC Nursing, 12(29).

Soilemezi, D., Drahota, A., Crossland, J., \& Stores, R. (2017). The role of the home environement in dementia care: Systematic review of qualitative research. Dementia, 18(4). DOI:10.1177/1471301217692130 
Turner, N., \& Morken, L. (2016). Better together: A comparative analysis of age-friendly and dementia-friendly communities. Washington, DC: AARP International Affairs.

Tuppen, J. (2012). The benefits of groups that provide cognitive stimulation for people with dementia. Nursing Older People, 24(10).

Tranvåg, O., Petersen, K., \& Nåden, D. (2015). Relational interactions preserving dignity experience: Perceptions of persons living with dementia. Nursing Ethics, 22(5), 577593. DOI: $10.1177 / 0969733014549882$

van Alphen, H., Hortobágyi, T., \& van Heuvelen, M. (2016). Barriers, motivators, and facilitators of physical activity in dementia patients: A systematic review. Archives of Gerontology and Geriatrics, 66, 109-118.

Vernooij-Dassen, M., \& Jeon, Y. H. (2016). Social health and dementia: the power of human capabilities. International Psychogeriatrics, 28, 701-703.

Ward, R., Clark, A., Campbell, S., Graham, B., Kullberg, A., Manji, K., Rummery, K., \& Keady, J. (2018). The lived neighbourhood: understanding how people with dementia engage with their local environment. International Psychogeriatrics, 30, 867-880.

Wiersma, E., \& Denton, A. (2016). From social network to safety net: Dementia-friendly communities in rural northern Ontario. Dementia, 15(1), 51-68.

Wiersma, E., O'Connor, D., Loiselle, L., Hickman, K., Heibein, B., Hounam, B., \& Mann, J. (2016). Creating space for citizenship: The impact of group structure on validating the voices of people with dementia. Dementia, 15(3). DOI: $10.1177 / 1471301216642339$

Wolverson, E. L., Clarke, C., \& Moniz-Cook, E. D. (2016). Living positively with dementia: a systematic review and synthesis of the qualitative literature. Aging \& Mental Health, 20(7). https://doi.org/10.1080/13607863.2015.1052777

World Health Organisation and Alzheimer's Disease International (2012). Dementia: A public health priority. London, England: World Health Organisation.

Wright, A. (2018). Exploring the relationship between community-based physical activity and wellbeing in people with dementia: a qualitative study. Ageing \& Society, 38, 522-542. DOI:10.1017/S0144686X16001124

Yin, R. (2010). Analytic generalisation. In A. Mills, G. Durepos, \& E. Wiebe (Eds.), Encyclopedia of case study research (pp. 21-23). London, England: Sage. 